\section{(2) OPEN ACCESS}

\title{
Treatment failure in giant cell arteritis
}

\author{
Sebastian H Unizony, ${ }^{1}$ Min Bao, ${ }^{2}$ Jian Han, ${ }^{2}$ Yves Luder, ${ }^{3}$ Andrey Pavlov, ${ }^{4}$ \\ John H Stone (iD) ${ }^{1}$
}

\begin{abstract}
Handling editor Josef $S$ Smolen

- Additional supplemental material is published online only. To view, please visit the journal online (http://dx.doi. org/10.1136/annrheumdis2021-220347).
\end{abstract}

For numbered affiliations see end of article.

\section{Correspondence to}

Dr John H Stone, Vasculitis and Glomerulonephritis Center,

Rheumatology, Immunology and Allergy Division, Massachusetts General Hospital, Boston, MA 02114, USA;

JHSTONE@mgh.harvard.edu

This work was presented, in part, at the 19th International Vasculitis and ANCA Workshop (Rheumatology, Volume 58, Issue Supplement_2, March 2019, kez063.082, https://doi. org/10.1093/rheumatology/ kez063.082), the European League Against Rheumatism congress 2019 (http://dx.doi. org/10.1136/annrheumdis2019-eular.2698) and the American College of Rheumatology congress 2019 (Arthritis Rheumatol. 2019; 71 (suppl 10). https://acrabstracts. org/abstract/risk-factors-fortreatment-failure-in-patientswith-giant-cell-arteritistreated-with-tocilizumab-plusprednisone-versus-prednisonealone/).

Received 12 March 2021 Accepted 24 May 2021

\section{Check for updates}

(C) Author(s) (or their employer(s)) 2021. Re-use permitted under CC BY-NC. No commercial re-use. See rights and permissions. Published by BMJ.

To cite: Unizony $\mathrm{SH}$

Bao M, Han J, et al.

Ann Rheum Dis Epub ahead

of print: [please include Day

Month Year]. doi:10.1136/

annrheumdis-2021-220347

\section{ABSTRACT}

Objective Identify predictors of treatment failure in patients with giant cell arteritis (GCA) receiving tocilizumab in combination with glucocorticoids and in patients with GCA receiving only glucocorticoids. Methods Posthoc analysis of the Giant-Cell Arteritis Actemra trial including 250 patients who received tocilizumab every week plus a 26 -week prednisone taper $(n=100)$, tocilizumab every-other-week plus a 26-week prednisone taper $(n=49)$ or placebo plus a 26-week $(n=50)$ or 52-week $(n=51)$ prednisone taper in the intention-to-treat population. Responders for this analysis were patients who maintained remission (no GCA signs/symptoms and no erythrocyte sedimentation rate elevation) through week 52 . Treatment failure was defined as inability to achieve remission by week 12 or relapse between weeks 12 and 52 . Predictors investigated in univariate and multivariable analyses included patient characteristics, disease-related and treatment-related factors and patient-reported outcomes (PROs).

Results 149 patients received tocilizumab plus prednisone (TCZ/PDN) and 101 received placebo plus prednisone (PBO+PDN). After adjustment for confounders, treatment failure was significantly less likely in the TCZ/PDN group than the PBO/PDN group (OR, 0.2; $95 \% \mathrm{Cl}, 0.1$ to $0.3 ; p<0.0001)$. Risk for treatment failure was significantly higher in women than men in the PBO/ PDN group (OR, 5.2; 95\% Cl, 1.6 to 17.2; $\mathrm{p}=0.007)$ but not in the TCZ/PDN group. Predictors of treatment failure in the TCZ/PDN group included lower baseline prednisone doses and worse PROs at baseline.

Conclusion The strongest risk factors for treatment failure in GCA are treatment with prednisone alone and female sex. Lower starting prednisone doses and impaired PROs are associated with failure to respond to tocilizumab.

Trial registration number NCT01791153.

\section{INTRODUCTION}

The clinical course of patients with giant cell arteritis (GCA) treated only with glucocorticoids has been complicated by high rates of disease relapse $(40 \%-$ $80 \%$ of patients) ${ }^{1-4}$ and frequent glucocorticoidrelated toxicity ( $>85 \%$ of cases). ${ }^{3-7}$ Interleukin-6 (IL-6) blockade therapy with tocilizumab has improved the outcomes of patients with GCA by decreasing the risk for relapse, reducing the cumulative exposure to glucocorticoids and improving patients' health-related quality of life..$^{8-13}$ Nevertheless, tocilizumab treatment is not successful in all patients, and approximately $25 \%-30 \%$ of them experience relapse while receiving this medication. $^{411}$

\section{Key messages}

What is already known about this subject?

- Most patients with giant cell arteritis (GCA) treated with glucocorticoids alone experience disease relapse and develop glucocorticoidrelated toxicity, and up to $30 \%$ of patients experience relapse while receiving tocilizumab.

- Risk factors for treatment failure have been investigated in patients with GCA treated only with glucocorticoids. However, a consistent profile defining risk for relapse across studies was not observed and findings were discrepant. Virtually nothing is known about the determinants for relapse in patients with GCA treated with tocilizumab.

\section{What does this study add?}

- Our analyses demonstrated that patients with GCA receiving tocilizumab in combination with prednisone were six times less likely to experience treatment failure than those receiving prednisone alone.

- Female sex was the strongest risk factor for treatment failure in prednisone only-treated patients, whereas lower prednisone doses and worse patient-reported outcomes at study baseline increased the risk for treatment failure in patients treated with tocilizumab.

How might this impact on clinical practice or
future developments?
Given the absence of biomarkers to assess the
risk for disease relapse in GCA, knowledge
of epidemiological, clinical and treatment-
related variables associated with poor disease
outcomes could help clinicians better stratify,
treat and monitor patients.
Women experience treatment failure
significantly more often than men when
receiving glucocorticoids alone, and tocilizumab
might mitigate this risk, whereas the discovery
that patient-reported outcomes predicted
treatment failure is a hypothesis generating
finding that should be further explored in future
studies.

Several studies have explored factors associated with disease relapse in patients with GCA treated only with glucocorticoids. ${ }^{31415}$ Identified predictors for treatment failure have included sex ${ }^{14}$ clinical features at disease onset (eg, polymyalgia rheumatica (PMR) symptoms, strong systemic inflammatory response and weight loss), ${ }^{3} 1617$ certain 
comorbidities (eg, diabetes) ${ }^{14}$ and increased serum proinflammatory cytokine levels (IL- 6 and tumour necrosis factor- $\alpha$ ). ${ }^{18}$ However, a consistent phenotype associated with treatment failure has not been identified, and results found in some studies have not always been replicated in others.

In contrast, virtually nothing is known about determinants for disease relapse in patients treated with tocilizumab. This problem, coupled with the unreliability of $\mathrm{C}$ reactive protein (CRP) levels and the erythrocyte sedimentation rate (ESR) for disease activity monitoring with IL-6 blockade therapy, ${ }^{4} 19$ makes the longitudinal care of patients with GCA treated with tocilizumab challenging.

Risk stratification of patients with GCA based on clinical predictors may assist clinicians in choosing the most appropriate treatment and monitoring regimens for each case. We aimed to identify predictors of treatment failure in patients with GCA who received prednisone alone or tocilizumab plus prednisone.

\section{METHODS}

\section{Study design and participants}

We performed a posthoc analysis of data from the randomised, placebo-controlled Giant-Cell Arteritis Actemra (GiACTA) trial (ClinicalTrials.gov, NCT01791153) ${ }^{8}$ to identify predictors of treatment failure because of refractory disease (failure to achieve disease remission over the first 12 weeks) or disease relapse following remission in patients with GCA. Details of the trial design have been published. ${ }^{20}$ The trial was conducted at 76 centres in 14 countries (see online supplemental appendix 1 for list of investigators). Patients with active disease within 6 weeks of baseline were randomly assigned in a 2:1:1:1 ratio to one of four treatment arms: tocilizumab $162 \mathrm{mg}$ subcutaneously every week plus a 26 -week prednisone taper $(n=100)$; tocilizumab $162 \mathrm{mg}$ subcutaneously every other week plus a 26-week prednisone taper $(n=50)$; placebo plus a 26 -week prednisone taper $(n=50)$ and placebo plus a 52-week prednisone taper $(n=51)$. The intention-to-treat population consisted of 250 patients because one patient who had been assigned to receive tocilizumab every other week did not receive the trial drug and was excluded from the analysis. For this analysis, the two tocilizumab plus prednisone arms were combined (TCZ/PDN group) and the two placebo plus prednisone arms were combined (PBO/PDN group).

Either glucocorticoid treatment for GCA was initiated or the previously used dose was maintained or modified during screening at the discretion of the investigators. At baseline, patients had to be receiving a daily prednisone dose between $20 \mathrm{mg}$ and $60 \mathrm{mg}$. From baseline through week 52, the prednisone dose was tapered as determined by the protocol.

Randomisation was performed using an interactive voice response system and was stratified according to whether each patient's baseline prednisone dose was $\leq 30$ or $>30 \mathrm{mg} /$ day. Patients were randomly assigned to receive tocilizumab or matching placebo by subcutaneous injection. Prednisone doses between $60 \mathrm{mg}$ and $20 \mathrm{mg}$ were administered open-label, and doses below $20 \mathrm{mg}$ were provided in weekly blister packs for blinded administration with marked daily doses that included prednisone or placebo capsules.

The GiACTA trial was approved by institutional review boards at the institutions involved and was conducted under the guidelines for Good Clinical Practice and the Declaration of Helsinki. All patients provided written informed consent.

\section{Outcome definitions and predictors}

Treatment response was defined as the achievement and maintenance of clinical remission from week 12 to week 52 with adherence to the protocol prednisone taper. Clinical remission status was determined by the investigators based on the absence of disease activity, defined as GCA signs and symptoms or ESR elevation attributable to GCA that required treatment intensification. The requirement for normalisation of CRP levels to $<1 \mathrm{mg} /$ $\mathrm{dL}$, which was part of the definition of remission for the primary analysis, ${ }^{8}$ was not included in the definition of clinical remission for the current analysis. Treatment failure was defined as failure to achieve clinical remission by week 12 (refractory disease) or relapse of disease activity between week 12 and week 52 after the achievement of clinical remission by week 12 .

Potential predictors of treatment failure included demographic and patient characteristics, disease features (eg, new-onset vs relapsing disease, duration of disease, clinical manifestations and levels of inflammatory markers), treatment-related factors (TCZ/ $\mathrm{PDN}$ vs PBO/PDN treatment group and initial prednisone dose) and patient-reported outcomes (PROs) (online supplemental box 1). The PROs evaluated were Patient Global Assessment of Disease Activity (PtGA) score, ${ }^{21}$ Functional Assessment of Chronic Illness Therapy (FACIT)-Fatigue scale, ${ }^{22}$ 36-Item Short Form Survey (SF-36) ${ }^{23}$ and EuroQol-5D (EQ-5D) score ${ }^{24}$ (online supplemental table 1). Except for data on clinical manifestations that reflected the time of disease presentation (ie, headache, scalp tenderness, jaw claudication, GCA-related visual loss, PMR symptoms, positive temporal artery biopsy and imaging demonstrating large-vessel vasculitis), all other predictor variables were measured at baseline.

\section{Statistical analysis}

All analyses were performed using SAS statistical software. Continuous data were described as means and SD or medians and IQR, and categorical variables were described as absolute frequencies and percentages. The Cochran-Mantel-Haenszel test was used to compare the proportions of patients who experienced treatment failure between the $\mathrm{PBO} / \mathrm{PDN}$ group and the TCZ/PDN group adjusted for baseline prednisone dose $(\leq 30 \mathrm{mg} /$ day or $>30 \mathrm{mg} /$ day). Univariate and multivariable analyses were performed to identify predictors of treatment failure in the entire cohort of patients as well as in the TCZ/PDN and $\mathrm{PBO} / \mathrm{PDN}$ groups separately. Variables considered for the analyses were initially selected based on current understanding of risk factors for poor treatment outcomes in GCA. Univariate comparisons were made using $t$ tests and $\chi^{2}$ tests for continuous and categorical data, respectively. Logistic regression was used for multivariable analyses and included treatment group and a set of variables chosen based on scientific rationale (new-onset vs relapsing disease, duration of disease, prednisone dose at baseline). Additionally, variables associated with treatment failure in univariate analyses of the entire cohort $(p<0.05)$ were entered in the multivariable models. Multicollinearity was examined using the variance inflation factors. PROs exhibited a high degree of collinearity and therefore were not allowed to enter a logistic regression model simultaneously. Results of the multivariable analyses were reported as estimated ORs for treatment failure, with corresponding 95\% CI. All analyses were exploratory, and no adjustment was made for type I error control.

\section{RESULTS}

Baseline characteristics of patients in the GiACTA trial cohort ${ }^{25}$ and the primary analysis ${ }^{8}$ are published. The 250 patients 
Table 1 Baseline characteristics of patients with GCA who met criteria for treatment response or failure

\begin{tabular}{|c|c|c|c|}
\hline & $\begin{array}{l}\text { PBO/PDN* } \\
(n=94)\end{array}$ & $\begin{array}{l}\text { TCZ/PDN* } \\
(n=130)\end{array}$ & $\begin{array}{l}\text { All patients* } \\
(n=224)\end{array}$ \\
\hline Age, years & $68.4(7.7)$ & $68.9(8.4)$ & $68.7(8.1)$ \\
\hline Female, n (\%) & $71.0(75.5)$ & $98.0(75.4)$ & $169.0(75.4)$ \\
\hline GCA duration, weeks & $43.7(73.6)$ & $41.9(78.9)$ & $42.7(76.6)$ \\
\hline Newly diagnosed disease, $\mathrm{n}(\%)$ & $45.0(47.9)$ & $66.0(50.8)$ & $111.0(49.6)$ \\
\hline $\begin{array}{l}\text { Cranial symptoms only or cranial } \\
\text { and PMR symptoms, } \mathrm{n}(\%)\end{array}$ & $75.0(79.8)$ & $103.0(79.2)$ & $178.0(79.5)$ \\
\hline PMR symptoms only, $n$ (\%) & $19.0(20.2)$ & $27.0(20.8)$ & $46.0(20.5)$ \\
\hline Cranial symptoms only, $\mathrm{n}(\%)$ & $33.0(35.1)$ & $51.0(39.2)$ & $84.0(37.5)$ \\
\hline $\begin{array}{l}\text { Baseline prednisone dose, } \mathrm{mg} / \\
\text { day, } \mathrm{n}(\%)\end{array}$ & $35.2(13.7)$ & $35.7(13.3)$ & $35.5(13.4)$ \\
\hline $\begin{array}{l}\text { Baseline prednisone dose } \leq 30 \mathrm{mg} / \\
\text { day, } \mathrm{n}(\%)\end{array}$ & $48.0(51.1)$ & $64.0(49.2)$ & $112.0(50.0)$ \\
\hline CRP, mg/L & $8.0(16.9)$ & $8.2(17.0)$ & $8.1(16.9)$ \\
\hline ESR, mm/hour & $25.6(21.4)$ & $23.2(17.7)$ & $24.2(19.4)$ \\
\hline PtGA, $100 \mathrm{~mm}$ VAS & $41.4(28.2)$ & $43.9(25.6)$ & $42.8(26.7)$ \\
\hline EQ-5D score & $0.7(0.2)$ & $0.7(0.2)$ & $0.7(0.2)$ \\
\hline FACIT-Fatigue score & $33.8(13.4)$ & $36.5(11.2)$ & $35.4(12.2)$ \\
\hline SF-36 MCS & $41.7(13.4)$ & $44.7(12.8)$ & $43.4(13.1)$ \\
\hline SF-36 PCS & $42.5(10.0)$ & $42.8(8.6)$ & $42.7(9.2)$ \\
\hline
\end{tabular}

Data are shown as mean (SD) unless specified otherwise.

* Does not include the 26 patients (seven TCZ/PDN, 19 PBO/PDN) who were non-responders for reasons other than treatment failure (see supplementary table 2) for reasons for nonresponse in this group)

CRP, C reactive protein; EQ-5D, EuroQol 5-D; ESR, erythrocyte sedimentation rate; FACIT, Functional Assessment of Chronic Illness Therapy; GCA, giant cell arteritis; MCS, Mental Component Summary; PBO/PDN, placebo+prednisone; PCS, Physical Component Summary; PMR, polymyalgia rheumatica; PtGA, Patient Global Assessment of Disease Activity; SF-36, 36-Item Short Form Survey; TCZ/PDN, tocilizumab+prednisone; VAS, visual analogue scale.

included in the intention-to-treat analysis (101 in the PBO/PDN group and 149 in the TCZ/PDN group) were 113 treatment responders (45.2\%) at week 52, 111 non-responders because of treatment failure (44.4\%) (refractory disease or disease relapse) and 26 non-responders because of other reasons (10.4\%) (online supplemental table 2). Table 1 depicts the baseline characteristics of the 224 patients (TCZ/PDN, n=130; PBO/PDN, n=94) defined as treatment responders or treatment failures, excluding the 26 classified as non-responders for reasons other than treatment failure.

\section{Risk for treatment failure}

Treatment regimen was the strongest predictor of treatment failure. Treatment response was achieved by 86 patients $(66.2 \%)$ in the TCZ/PDN group and 27 patients (28.7\%) in the PBO/ PDN group (table 2). Accordingly, rates of treatment failure were significantly lower in the TCZ/PDN group than the PBO/PDN group $(33.8 \%$ vs $71.3 \%$; $<0.0001)$. In multivariable logistic regression adjusting for disease duration, baseline prednisone dose, previous disease relapse and sex, the OR for treatment

Table 2 Rates of treatment response and treatment failure

\begin{tabular}{llll}
\hline & PBO/PDN $(\mathrm{n}=94)$ & TCZ/PDN $(\mathrm{n=130)}$ & P value * $^{*}$ \\
\hline Treatment response, $\mathrm{n}(\%)$ & $27(28.7)$ & $86(66.2)$ & \\
Treatment failure, $\mathrm{n}(\%)$ & $67(71.3)$ & $44(33.8)$ & $<0.0001$ \\
$\quad$ Refractory disease & $31(33.0)$ & $18(13.8)$ & \\
\multicolumn{1}{c}{ Disease relapse } & $36(38.3)$ & $26(20.0)$ & \\
\hline
\end{tabular}

*Cochran-Mantel-Haenszel test comparing the proportions of patients with

treatment failure between the PBO/PDN group and the TCZ/PDN group adjusted for baseline prednisone dose ( $\leq 30 \mathrm{mg} /$ day or $>30 \mathrm{mg} /$ day).

PBO/PDN, placebo+prednisone; TCZ/PDN, tocilizumab+prednisone. failure in the TCZ/PDN group versus the PBO/PDN group was 0.2 (95\% CI, 0.1 to $0.3 ; \mathrm{p}<0.0001$ ) (figure $1 \mathrm{~A})$. In addition, in the TCZ/PDN group, patients receiving $\leq 30 \mathrm{mg}$ prednisone/day at baseline were at higher risk for treatment failure than those receiving $>30 \mathrm{mg} /$ day (OR 2.4; $95 \% \mathrm{CI}, 1.0$ to $5.9 ; \mathrm{p}=0.046$ ) (figure 1B). However, baseline prednisone dose did not predict treatment failure in patients in the PBO/PDN group (figure 1C).

In unadjusted analysis of the entire cohort, women accounted for $85.6 \%$ of the treatment failures and $65.5 \%$ of the treatment responses $(p=0.0005$; table 3$)$. When the analysis was limited to each treatment group, results showed that among PBO/PDNtreated patients, women were significantly over-represented in the treatment failure group and under-represented in the treatment response group (86.6\% vs $48.1 \%$; $<<0.0001$; table 4 ), but a difference in outcome according to sex was not observed in TCZ/PDN-treated patients. Multivariable analysis confirmed female sex as an independent risk factor for treatment failure among $\mathrm{PBO} / \mathrm{PDN}$ recipients (OR 5.5; 95\% CI 1.6 to 18.7 ; $\mathrm{p}=0.006$ ) but not among TCZ/PDN recipients (OR 2.3; 95\% CI 0.8 to $6.7 ; p=0.12$; Figure $1 B, C$ ). Age, race and body mass index were not associated with treatment outcome (tables 3 and 4).

\section{Disease-related features as predictors of treatment failure}

Jaw claudication and PMR symptoms at GCA diagnosis were associated with treatment failure in univariate and multivariable analyses of the entire cohort (table 3, figure 1A). When each treatment group was analysed separately, however, only jaw claudication came close to achieving statistical significance as a clinical feature that independently predicted treatment failure among the TCZ/PDN-treated patients (OR 2.3; 95\% CI 1.0 to $5.5 ; \mathrm{p}=0.06$ ) (figure $1 \mathrm{~B}$ ). In contrast, no clinical manifestations independently predicted treatment failure in the PBO/PDN group (figure 1C). Moreover, there were no significant differences in treatment outcome associated with duration of disease, disease type (new-onset vs relapsing disease), baseline level of ESR and CRP or presence of large vessel vasculitis identified by imaging at the time of GCA diagnosis (all p >0.05; tables 3 and 4; figure 1).

\section{Relationship between PROs and treatment failure}

Univariate analyses showed that lower baseline health-related quality of life and increased baseline patient perception of disease activity were associated with treatment outcome. In analyses of the entire cohort (table 3), PtGA scores were significantly higher (ie, worse) in patients who experienced treatment failure $(p=0.012)$. Accordingly, these patients had significantly lower (ie, worse) FACIT-Fatigue $(\mathrm{p}<0.0001)$, SF-36 Physical Component Summary (PCS) $(\mathrm{p}=0.0002)$, SF-36 Mental Component Summary (MCS) $(p=0.0023)$ and EQ-5D $(p=0.0064)$ scores. When treatment groups were analysed separately (table 4), a statistically significant association was found between PROs and treatment failure for all PROs $(\mathrm{p}<0.05)$ except PtGA $(\mathrm{p}=0.46)$ and EQ-5D $(\mathrm{p}=0.14)$ in $\mathrm{PBO} / \mathrm{PDN}$-treated patients and SF-36 MCS $(p=0.11)$ in TCZ/PDN-treated patients.

To explore the independent effect of PROs on treatment outcome while avoiding the problem of collinearity associated with these tools, we constructed logistic regression models that included one PRO at a time. Covariates included in the models were treatment group (TCZ/PDN vs $\mathrm{PBO} / \mathrm{PDN}$ ), baseline prednisone dose, sex, duration of disease, new-onset versus relapsing disease at baseline, PMR and jaw claudication. Baseline PROs independently predicted treatment failure among TCZ/PDNtreated patients but not among $\mathrm{PBO} / \mathrm{PDN}$-treated patients 
A

Treatment (tocilizumab+prednisone vs placebo+prednisone)

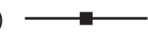

$<0.0001$

Baseline SF36 Physical Component (per 10 point increase)

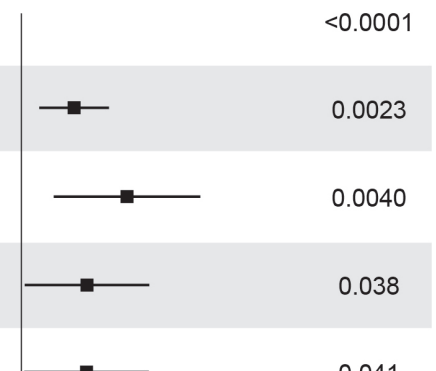

Jaw Claudication (yes vs no)

Prednisone Dose at Baseline ( $\leq 30 \mathrm{mg} /$ day vs $>30 \mathrm{mg} /$ day)

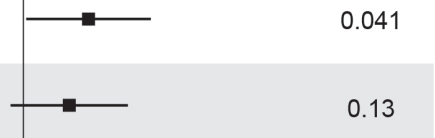

Duration of GCA (per 1 year decrease)

Disease Onset (relapsing vs new-onset)

B

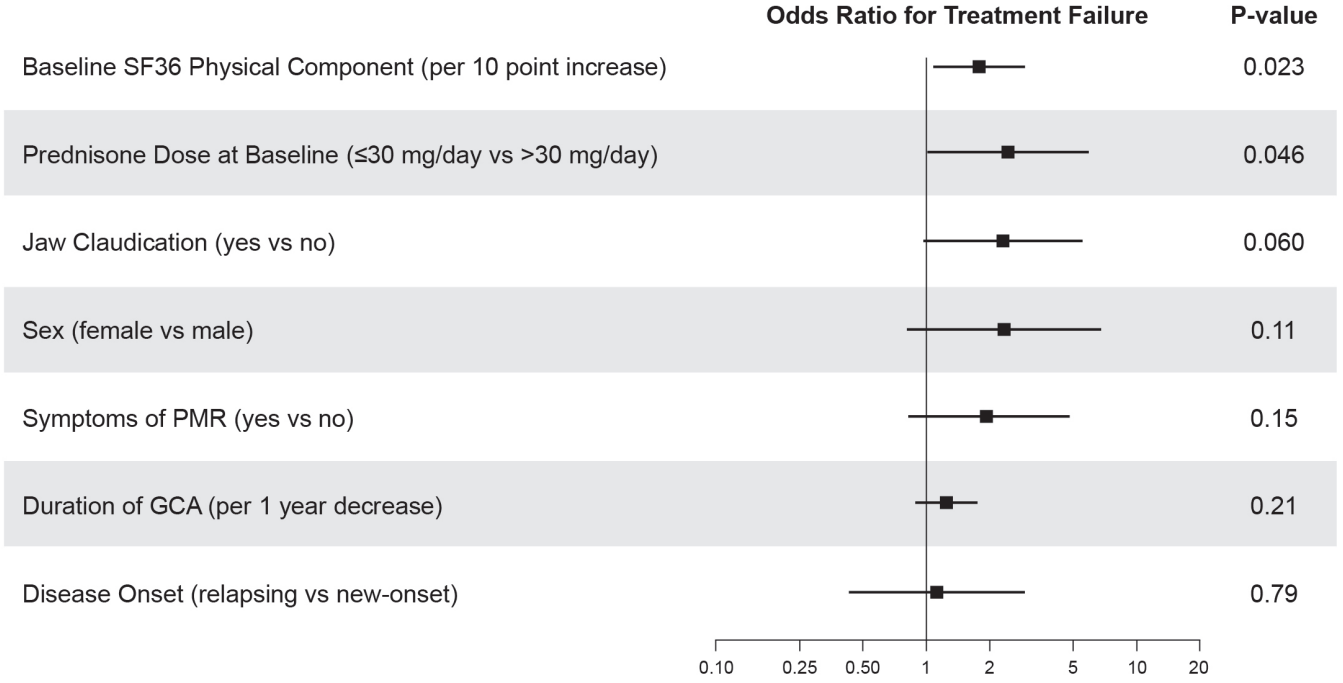

C

Odds Ratio for Treatment Failure P-value

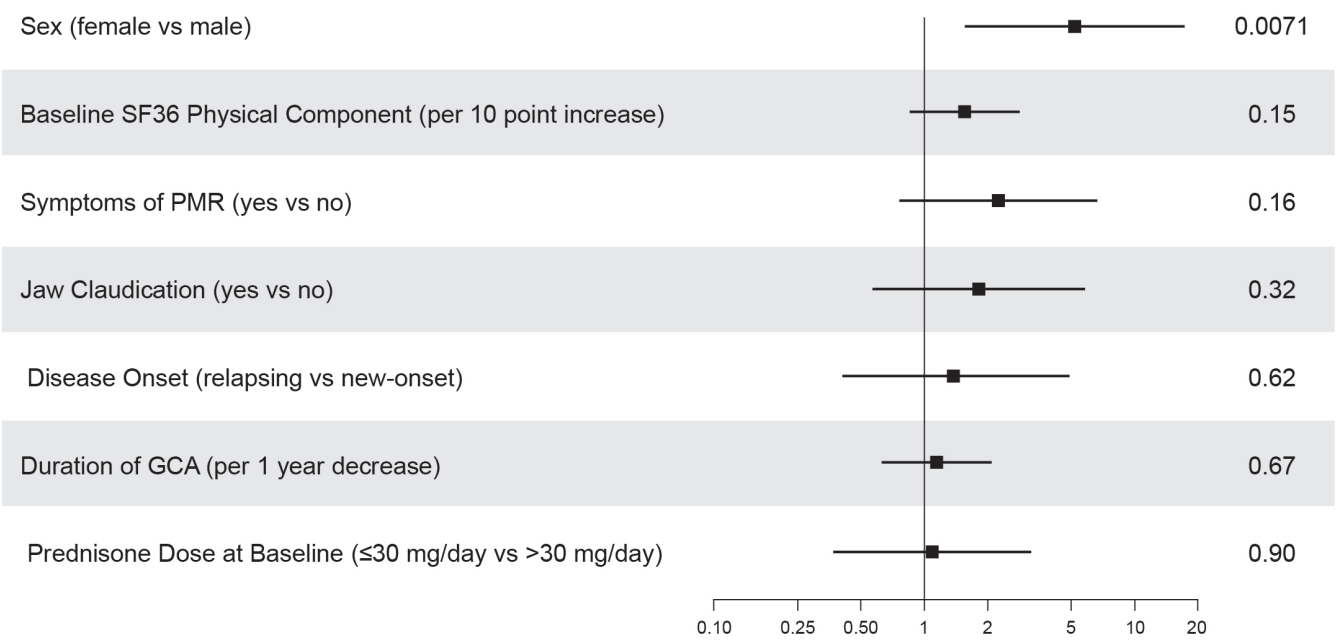

Figure 1 Multivariable analysis of treatment failure (PRO SF-36 Physical Component Summary) for the (A) entire cohort, (B) tocilizumab+prednisone group and (C) placebo+prednisone group. GCA, giant cell arteritis; PMR, polymyalgia rheumatica; PRO, patient-reported outcome; SF-36, 36-Item Short Form Survey. 
Table 3 Univariate analysis of treatment failure (intention-to-treat population with treatment outcome defined)

\begin{tabular}{|c|c|c|c|}
\hline Characteristic & $\begin{array}{l}\text { Treatment } \\
\text { response }(n=113)\end{array}$ & $\begin{array}{l}\text { Treatment failure } \\
(\mathrm{n}=111)\end{array}$ & $P$ value \\
\hline \multicolumn{4}{|l|}{ Patient-related features } \\
\hline Age, years, mean (SD) & $68.4(8.3)$ & $68.9(7.9)$ & 0.64 \\
\hline Female sex, n (\%) & $74(65.5)$ & $95(85.6)$ & 0.00051 \\
\hline White, $n(\%)$ & $110(97.3)$ & $109(98.2)$ & 0.51 \\
\hline BMI, mean (SD) & $26.1(4.3)$ & $25.7(4.5)$ & 0.52 \\
\hline \multicolumn{4}{|l|}{ Disease-related features } \\
\hline \multicolumn{4}{|c|}{ At the time of GCA diagnosis, $n(\%)$} \\
\hline Headaches & $83(73.5)$ & $70(63.1)$ & 0.095 \\
\hline Scalp tenderness & $40(35.4)$ & $38(34.2)$ & 0.85 \\
\hline Jaw claudication & $30(26.5)$ & $44(39.6)$ & 0.037 \\
\hline GCA-related vision loss & $8(7.1)$ & $10(9.0)$ & 0.60 \\
\hline PMR symptoms & $62(54.9)$ & $78(70.3)$ & 0.017 \\
\hline $\begin{array}{l}\text { Positive temporal artery } \\
\text { biopsy }\end{array}$ & $66 / 76(86.8)$ & $71 / 76(93.4)$ & 0.17 \\
\hline $\begin{array}{l}\text { Imaging demonstrating } \\
\text { LVV }\end{array}$ & $56 / 62(90.3)$ & $50 / 61(82.0)$ & 0.18 \\
\hline \multicolumn{4}{|l|}{ At study baseline } \\
\hline $\begin{array}{l}\text { New-onset disease, } \\
\mathrm{n}(\%)\end{array}$ & $61(54)$ & $50(45)$ & 0.18 \\
\hline $\begin{array}{l}\text { GCA duration, weeks, } \\
\text { mean (SD) }\end{array}$ & $37.9(75.1)$ & $47.5(78.1)$ & 0.35 \\
\hline $\begin{array}{l}\text { ESR, mm/hour, mean } \\
\text { (SD) }\end{array}$ & $22.5(17.9)$ & $26.0(20.7)$ & 0.18 \\
\hline CRP, mg/dL, mean (SD) & $6.6(11.2)$ & $9.7(21.2)$ & 0.17 \\
\hline \multicolumn{4}{|l|}{ Treatment-related features } \\
\hline $\begin{array}{l}\text { Baseline prednisone } \\
\text { dose, mg/day, mean (SD) }\end{array}$ & $36.0(13.4)$ & $34.9(13.5)$ & 0.56 \\
\hline \multicolumn{4}{|l|}{ Patient-reported outcomes } \\
\hline PtGA, mm, mean (SD) & $38.4(26.8)$ & $47.4(25.9)$ & 0.012 \\
\hline $\begin{array}{l}\text { FACIT-Fatigue scale, } \\
\text { mean (SD) }\end{array}$ & $39.0(10.6)$ & $31.7(12.7)$ & $<0.0001$ \\
\hline SF-36 PCS, mean (SD) & $44.9(8.5)$ & $40.4(9.3)$ & 0.00021 \\
\hline SF-36 MCS, mean (SD) & $46.0(11.8)$ & 40.7 (13.9) & 0.0023 \\
\hline EQ-5D score, mean (SD) & $0.8(0.2)$ & $0.7(0.2)$ & 0.0064 \\
\hline
\end{tabular}

BMI, body mass index; CRP, C reactive protein; EQ-5D, EuroQol-5D; ESR, erythrocyte sedimentation rate; FACIT-Fatigue, Functional Assessment of Chronic Illness Therapy-Fatigue scale; GCA, giant cell arteritis; LVV, large vessel vasculitis; MCS, Mental Component Summary; PCS, Physical Component Summary; PMR, polymyalgia rheumatica; PtGA, Patient Global Assessment of Disease Activity; SF-36, 36-Item Short Form Survey.

(table 5, figure 1). In the TCZ/PDN group, SF-36 PCS and FACIT-Fatigue demonstrated relatively larger effects on treatment outcome with ORs for treatment failure of 1.8 (95\% CI 1.1 to $2.9 ; p=0.02)$ and $1.8(95 \%$ CI 1.2 to $2.6 ; p=0.002)$, respectively, for every 10-point decrease in a score at baseline (table 5, figure $1 \mathrm{~B}$ ).

\section{DISCUSSION}

Treatment failure has major implications for patients with GCA because of disease-associated morbidity and because of the need for additional glucocorticoid therapy, which nearly always leads to treatment-induced toxicity. ${ }^{3-7} 26$ The absence of reliable biomarkers to monitor disease activity ${ }^{14}$ and to predict treatment failure poses a significant challenge in GCA management. Our analysis identified independent predictors of treatment failure in GCA. These include the use of glucocorticoid monotherapy in general. In addition, a sharp disparity between women and men was observed among patients treated with prednisone alone: women had a strikingly higher risk for treatment failure, reflected by an OR of 5.2. Among patients randomly assigned to tocilizumab-based regimens, lower initial prednisone doses and worse PROs were significant predictors of treatment failure.

Few studies have explored factors associated with relapse in patients receiving glucocorticoids alone, ${ }^{314} 15$ but the identification of a consistent phenotype associated with treatment failure has been elusive. Predictors previously identified include sex, ${ }^{14}$ clinical features at disease onset (eg, PMR symptoms and significant weight loss), ${ }^{31617}$ certain comorbidities (eg, diabetes) ${ }^{14}$ and increased serum IL-6 levels. ${ }^{18}$ Our findings confirm that female sex is a major risk factor for GCA-the disease occurs three times more frequently in women than in men-and a predictor of disease severity. ${ }^{142728}$ We observed that the risk for treatment failure was fivefold higher in women receiving prednisone alone, but the differential response according to sex did not reach statistical significance in women assigned to tocilizumab. Comparison of the risk for treatment failure in women and men assigned to tocilizumab fell short of statistical significance, yet the OR for treatment failure among women was 2.3. These disparities in outcomes defined by sex are noteworthy because, on a per kilogram basis, women received more therapy-glucocorticoids and tocilizumab-than men. Thus, although IL- 6 signalling blockade therapy represents a major advance for patients with GCA in general and an important step forward for women with this disease, a crucial unanswered question is why women with GCA are more likely to experience treatment failure with current regimens, particularly glucocorticoids. The finding is not dissimilar to the fact that women are at greater risk for many immune-mediated conditions, such as systemic lupus erythematosus, and that they often have more severe disease courses than men. The basis for these differences in disease expression across the sexes is, in fact, one of the central mysteries of rheumatic disease. In GCA, between-sex genetic differences localised to the $\mathrm{X}$ chromosome, the role of sex hormones (although GCA generally occurs in the postmenopausal population) and differences in body composition between women and men are all worthy of further investigation.

Although the introduction of tocilizumab has altered the standard of care for GCA, ${ }^{89}$ treatment failure attributed to refractory disease or disease relapse occurs in nearly $30 \%$ of patients, which may indicate that inflammatory pathways independent from IL-6 can predominate in some cases. No studies have addressed the risk factors for disease flare among tocilizumabtreated patients. After adjusting for potential confounders, we quantified the therapeutic effect of tocilizumab and observed that its use decreased the risk for treatment failure by approximately fivefold compared with treatment regimens containing prednisone alone. In addition, among patients receiving tocilizumab, baseline prednisone doses lower than $30 \mathrm{mg} /$ day were associated with decreased likelihood of long-term disease control, possibly because in tocilizumab-treated patients starting on higher doses of prednisone, the prednisone tapering schedule dictated that a longer time was needed to reach low prednisone doses, when the risk for flare begins to rise substantially. This longer interval probably permitted more time for the downstream effects of tocilizumab to be fully realised.

In contrast, similar to observations in other studies, 2141629 we found no association between treatment outcome and initial glucocorticoid dose in patients treated with prednisone alone. This suggests that the risk for relapse in patients treated with prednisone alone is determined less by the duration of the glucocorticoid taper than by the dose of prednisone a patient is 
Table 4 Univariate analysis of treatment failure according to treatment (intention-to-treat population with treatment outcome defined)

\begin{tabular}{|c|c|c|c|c|c|c|}
\hline & $\begin{array}{l}\text { TCZ/PDN response } \\
(\mathrm{n}=86)\end{array}$ & TCZ/PDN failure $(n=44)$ & $P$ value & $\begin{array}{l}\text { PBO/PDN response } \\
(n=27)\end{array}$ & $\begin{array}{l}\text { PBO/PDN failure } \\
(n=67)\end{array}$ & $P$ value \\
\hline \multicolumn{7}{|l|}{ Patient-related features } \\
\hline Age, years, mean (SD) & $68.7(8.2)$ & $69.2(8.8)$ & 0.79 & $67.4(8.4)$ & $68.8(7.4)$ & 0.43 \\
\hline Female sex, $\mathrm{n}(\%)$ & $61(70.9)$ & $37(84.1)$ & 0.99 & $13(48.1)$ & $58(86.6)$ & $<0.0001$ \\
\hline White, $n(\%)$ & $84(97.7)$ & $43(97.7)$ & 0.29 & $26(96.3)$ & $66(98.5)$ & 0.50 \\
\hline BMI, mean (SD) & $26.1(4.4)$ & $25.7(4.9)$ & 0.66 & $26.0(4.1)$ & $25.7(4.3)$ & 0.72 \\
\hline \multicolumn{7}{|c|}{ Disease-related features } \\
\hline \multicolumn{7}{|c|}{ At the time of GCA diagnosis, $n(\%)$} \\
\hline Headaches & $65(75.6)$ & $28(63.6)$ & 0.15 & $18(66.7)$ & $42(62.7)$ & 0.72 \\
\hline Scalp tenderness & $30(34.9)$ & $18(40.9)$ & 0.50 & $10(37.0)$ & $20(29.9)$ & 0.50 \\
\hline Jaw claudication & $24(27.9)$ & $18(40.9)$ & 0.13 & $6(22.2)$ & $26(38.8)$ & 0.12 \\
\hline GCA-related vision loss & $5(5.8)$ & $4(9.1)$ & 0.49 & $3(11.1)$ & $6(9.0)$ & 0.75 \\
\hline PMR symptoms & $48(55.8)$ & $31(70.5)$ & 0.11 & $14(51.9)$ & $47(70.1)$ & 0.093 \\
\hline $\begin{array}{l}\text { Positive temporal artery } \\
\text { biopsy }\end{array}$ & $50 / 59(84.7)$ & $27 / 27(100.0)$ & 0.032 & $16 / 17(94.1)$ & $44 / 49(89.8)$ & 0.59 \\
\hline $\begin{array}{l}\text { Imaging demonstrating } \\
\text { LVV }\end{array}$ & $44 / 49(89.8)$ & $21 / 25(84.0)$ & 0.47 & $12 / 13(92.3)$ & $29 / 36(80.6)$ & 0.33 \\
\hline \multicolumn{7}{|l|}{ At study baseline } \\
\hline New-onset disease, $\mathrm{n}(\%)$ & $45(52.3)$ & $21(47.7)$ & 0.62 & $16(59.3)$ & $29(43.3)$ & 0.16 \\
\hline $\begin{array}{l}\text { GCA duration, weeks, } \\
\text { mean (SD) }\end{array}$ & $42.4(80.8)$ & $40.9(76.0)$ & 0.92 & $23.6(51.2)$ & $51.8(79.8)$ & 0.093 \\
\hline ESR, mm/hour, mean (SD) & $23.6(18.3)$ & $22.6(16.7)$ & 0.77 & $19.1(16.3)$ & $28.2(22.7)$ & 0.063 \\
\hline CRP, mg/dL, mean (SD) & $6.9(12.1)$ & $10.9(23.7)$ & 0.21 & $5.7(7.4)$ & $9.0(19.5)$ & 0.40 \\
\hline \multicolumn{7}{|c|}{ Treatment-related features } \\
\hline $\begin{array}{l}\text { Baseline prednisone dose, } \\
\mathrm{mg} / \text { day, mean (SD) }\end{array}$ & $36.3(12.9)$ & $34.3(14.2)$ & 0.42 & $34.8(15.2)$ & $35.3(13.1)$ & 0.88 \\
\hline \multicolumn{7}{|l|}{ Patient-reported outcomes } \\
\hline PtGA: mm, mean (SD) & $38.6(26.4)$ & $54.3(20.5)$ & 0.0008 & $38.0(28.8)$ & $42.8(28.1)$ & 0.46 \\
\hline $\begin{array}{l}\text { FACIT-Fatigue scale, } \\
\text { mean (SD) }\end{array}$ & $38.8(10.8)$ & $32.0(10.7)$ & 0.0008 & $39.4(10.2)$ & $31.6(13.9)$ & 0.011 \\
\hline SF-36 PCS, mean (SD) & $44.2(8.4)$ & $39.9(8.3)$ & 0.0076 & $47.2(8.7)$ & 40.7 (9.9) & 0.0044 \\
\hline SF-36 MCS, mean (SD) & $46.0(11.7)$ & $42.1(14.6)$ & 0.11 & $46.4(12.4)$ & $39.8(13.4)$ & 0.033 \\
\hline EQ-5D score, mean (SD) & $0.8(0.2)$ & $0.7(0.2)$ & 0.027 & $0.8(0.2)$ & $0.7(0.2)$ & 0.14 \\
\hline
\end{tabular}

BMI, body mass index; CRP, C reactive protein; EQ-5D, EuroQol-5D; ESR, erythrocyte sedimentation rate; FACIT-Fatigue, Functional Assessment of Chronic Illness Therapy-Fatigue scale; LVV, large vessel vasculitis; MCS, Mental Component Summary; PBO/PDN, placebo+prednisone; PCS, Physical Component Summary; PMR, polymyalgia rheumatica; PtGA, Patient Global Assessment of Disease Activity; SF-36, 36-Item Short Form Survey; TCZ/PDN, tocilizumab+prednisone.

receiving at a particular time. Stated another way, once prednisone is tapered to a certain daily dose (ie, a threshold), the risk for relapse increases, regardless of how long it takes for that dose level to be reached in a patient. Maintaining each patient at a prednisone dose above the flare threshold is likely to reduce the risk for relapse but can cause glucocorticoid toxicity to accumulate if that threshold is sufficiently high. One practical effect of tocilizumab appears to be lowering the prednisone threshold at which GCA flare is likely to occur.

We identified that PROs measuring functional health, well-being and subjective perception of disease activity were independently associated with treatment failure in tocilizumabtreated patients. Why PROs at baseline predicted treatment outcome only in the tocilizumab group is not entirely clear. IL-6 signalling is involved in the pathogenesis of sarcopaenia and frailty, ${ }^{30}$ which can contribute to fatigue and other manifestations captured by the PRO instruments used in this study. We hypothesise that impaired health-related quality of life in GCA could reflect higher IL-6 levels that are not fully suppressed by IL-6 signalling blockade once glucocorticoids have been discontinued. Baseline PROs were measured for most patients when they were receiving high doses of prednisone to control their disease activity before they enrolled in GiACTA. It seems logical, therefore, that patients whose PRO scores were impaired despite high-dose prednisone treatment would be at greater risk for treatment failure during the trial. In contrast, because most patients receiving only glucocorticoids during the trial experienced treatment failure, PROs could not discriminate between two putative IL-6 states. Additionally, low statistical power attributed to the small sample size of the PBO/PDN group may, in part, explain the lack of association between PRO measures and treatment failure in patients receiving prednisone alone. The association between PRO scores and increased risk for treatment failure in tocilizumab-treated patients might also be driven by other disease mechanism pathways independently of IL-6.

Our study has certain limitations. First, it was a posthoc analysis of data from a clinical trial that was not specifically powered for the comparisons of interest. Second, because the two groups assessed in this exploratory analysis were different from those originally randomly assigned, bias from unevenly distributed unknown covariates could have been introduced. Nevertheless, our multivariable analyses accounted for the most important known confounders. Finally, the urgency with which GCA must be treated to prevent blindness precluded the collection of samples from patients with untreated active disease to measure inflammatory markers, including IL-6 levels. In fact, 
Table 5 Multivariable analysis of PRO measures as predictors of treatment failure

\begin{tabular}{|c|c|c|c|}
\hline & OR & $95 \% \mathrm{Cl}$ & $P$ value \\
\hline \multicolumn{4}{|c|}{ SF-36 PCS (per 10-point decrease) } \\
\hline All patients & 1.8 & 1.2 to 2.6 & 0.0023 \\
\hline TCZ/PDN group & 1.8 & 1.1 to 2.9 & 0.023 \\
\hline PBO/PDN group & 1.6 & 0.9 to 2.8 & 0.15 \\
\hline \multicolumn{4}{|c|}{ FACIT-Fatigue scale (per 10-point decrease) } \\
\hline All patients & 1.6 & 1.2 to 2.2 & 0.00081 \\
\hline TCZ/PDN group & 1.8 & 1.2 to 2.6 & 0.0028 \\
\hline PBO/PDN group & 1.3 & 0.8 to 2.1 & 0.27 \\
\hline \multicolumn{4}{|c|}{ PtGA (per 10-point increase) } \\
\hline All patients & 1.2 & 1.0 to 1.3 & 0.028 \\
\hline TCZ/PDN group & 1.3 & 1.1 to 1.5 & 0.0078 \\
\hline PBO/PDN group & 1.0 & 0.8 to 1.2 & 0.99 \\
\hline \multicolumn{4}{|c|}{ SF-36 MCS (per 10-point decrease) } \\
\hline All patients & 1.3 & 1.0 to 1.7 & 0.040 \\
\hline TCZ/PDN group & 1.3 & 1.0 to 1.8 & 0.090 \\
\hline PBO/PDN group & 1.2 & 0.8 to 1.9 & 0.42 \\
\hline \multicolumn{4}{|c|}{ EQ-5D score (per 0.1-point decrease) } \\
\hline All patients & 1.2 & 1.0 to 1.4 & 0.063 \\
\hline TCZ/PDN group & 1.2 & 1.0 to 1.5 & 0.038 \\
\hline PBO/PDN group & 1.0 & 0.8 to 1.3 & 0.85 \\
\hline
\end{tabular}

Each model included a single PRO and the following predictor variables: duration of disease at baseline, prednisone dose at baseline, new-onset vs relapsing disease at baseline, sex, PMR symptoms at GCA diagnosis, jaw claudication at GCA diagnosis and (for analysis of all patients) PBO/PDN vs TCZ/PDN treatment.

EQ-5D, EuroQol-5D; FACIT-Fatigue, Functional Assessment of Chronic Illness Therapy-Fatigue scale; GCA, giant cell arteritis; MCS, Mental Component Summary; PBO/PDN, placebo+prednisone; PCS, physical component summary; PMR, polymyalgia rheumatica; PRO, patient-reported outcome; PtGA, Patient Global Assessment of Disease Activity; SF-36, 36-Item Short Form Survey; TCZ/PDN, tocilizumab+prednisone.

most patients were already in glucocorticoid-induced remission before the baseline visit. ${ }^{4}$ Therefore, the key question of whether impaired PROs at baseline were directly related to stronger inflammatory responses or higher IL-6 levels could not be tested. Along those lines, the fact that nearly all patients in the trial were started on prednisone during the screening period or even before the screening period-a measure that was appropriate and necessary-means that our ability to analyse the relationship between the level of the inflammatory state as reflected in baseline acute-phase reactants was limited. Future studies might aim to target this question more specifically, though obtaining samples from large numbers of patients before glucocorticoid therapy begins is challenging because of the urgency with which treatment must be initiated in GCA.

Our study has several strengths. First, our results were derived from prospectively collected data from the largest randomised, double-blind, placebo-controlled clinical trial in GCA. ${ }^{8}$ During the trial, the prednisone taper was standardised and prednisone doses lower than $20 \mathrm{mg} /$ day were administered in a blinded manner to prevent bias. ${ }^{32}$ Second, our definition of relapse aligns with that commonly used in clinical practice, which includes the presence of clinical signs or symptoms of GCA with or without increased ESR levels necessitating treatment. ${ }^{314}{ }^{17}$ Of note, most relapses in this study were diagnosed after the manifestation of clinical signs or symptoms, with or without concomitant ESR elevation, and only nine relapses were determined based on the presence of an isolated elevation in ESR. Third, this is the first study to analyse predictors of treatment failure in patients with
GCA receiving tocilizumab-based regimens, which are becoming the standard of care in this disease and for which more research is needed.

In summary, we identified important risk factors for treatment failure in GCA, the two strongest of which are prednisone monotherapy and female sex. Future studies might focus on elucidating the reasons for the striking disparity between men and women in risk for treatment failure, and future clinical trials must analyse in detail the impact of sex on treatment outcome.

\section{Author affiliations}

'Vasculitis and Glomerulonephritis Center, Rheumatology, Immunology and Allergy

Division, Massachusetts General Hospital, Boston, Massachusetts, USA

${ }^{2}$ Genentech Inc, South San Francisco, California, USA

${ }^{3} \mathrm{~F}$ Hoffmann-La Roche Ltd, Basel, Switzerland

${ }^{4}$ Everest Clinical Research, Markham, Ontario, Canada

Correction notice This article has been corrected since it published Online First. Figure 1 has been replaced.

Contributors Conceptualised and designed study: SHU, YL, JHS. Acquired data: SHU, MB, JHS. Analysed and interpreted data: SHU, MB, JH, YL, AP, JHS. Drafted manuscript: SHU, MB. Critically revised manuscript for important intellectual content: All authors. Approved submission of the manuscript for publication: All authors

Funding The study was funded by the sponsor, F Hoffmann-La Roche Ltd. The sponsor was involved in the study design and conduct, in the analysis, interpretation and reporting of data and in the decision to submit the manuscript for publication. The corresponding author had full access to all data in the study and had final responsibility for the decision to submit the manuscript for publication.

Competing interests SHU has received research funding from Roche/Genentech. $M B, J H$ and $Y L$ own stock in and are employees of $F$ Hoffmann-La Roche Ltd. AP is an employee of Everest Clinical Research, which received payment from Genentech for the submitted work. JHS has received research funding from Roche/Genentech and consulting fees from Chugai and Roche/Genentech.

\section{Patient consent for publication Not required.}

Ethics approval The study was conducted under the guidelines for Good Clinical Practice and the Declaration of Helsinki and was approved by institutional review boards at the institutions involved. All patients provided written informed consent.

Provenance and peer review Not commissioned; externally peer reviewed.

Data availability statement Data are available on reasonable request. Qualified researchers may request access to individual patient level data through the clinical study data request platform (https://vivli.org/). Further details on Roche's criteria for eligible studies are available here (https://vivli.org/members/ourmembers/). For further details on Roche's Global Policy on the Sharing of Clinical Information and how to request access to related clinical study documents, see here (https://www. roche.com/research_and_development/who_we_are_how_we_work/clinical_trials/ our_commitment_to_data_sharing.htm).

Supplemental material This content has been supplied by the author(s). It has not been vetted by BMJ Publishing Group Limited (BMJ) and may not have been peer-reviewed. Any opinions or recommendations discussed are solely those of the author(s) and are not endorsed by BMJ. BMJ disclaims all liability and responsibility arising from any reliance placed on the content. Where the content includes any translated material, BMJ does not warrant the accuracy and reliability of the translations (including but not limited to local regulations, clinical guidelines, terminology, drug names and drug dosages), and is not responsible for any error and/or omissions arising from translation and adaptation or otherwise.

Open access This is an open access article distributed in accordance with the Creative Commons Attribution Non Commercial (CC BY-NC 4.0) license, which permits others to distribute, remix, adapt, build upon this work non-commercially, and license their derivative works on different terms, provided the original work is properly cited, appropriate credit is given, any changes made indicated, and the use is non-commercial. See: http://creativecommons.org/licenses/by-nc/4.0/.

\section{ORCID iD}

John H Stone http://orcid.org/0000-0001-6588-9435

\section{REFERENCES}

1 Kermani TA, Warrington KJ, Cuthbertson D, et al. Disease relapses among patients with giant cell arteritis: a prospective, longitudinal cohort study. J Rheumatol 2015:42:1213-7.

2 Martinez-Lado L, Calviño-Díaz C, Piñeiro A. Relapses and recurrences in giant cell arteritis: a population-based study of patients with biopsy-proven disease from northwestern Spain. Medicine 2011;90:186-93. 
3 Alba MA, Garcia-Martinez A, Prieto-Gonzalez S. Relapses in patients with giant cell arteritis: prevalence, characteristics, and associated clinical findings in a longitudinally followed cohort of 106 patients. Medicine 2014;93:194-201.

4 Stone JH, Tuckwell K, Dimonaco S, et al. Glucocorticoid dosages and Acute-Phase reactant levels at giant cell arteritis flare in a randomized trial of tocilizumab. Arthritis Rheumatol 2019;71:1329-38.

5 Proven A, Gabriel SE, Orces C, et al. Glucocorticoid therapy in giant cell arteritis: duration and adverse outcomes. Arthritis Rheum 2003;49:703-8.

6 Petri H, Nevitt A, Sarsour K, et al. Incidence of giant cell arteritis and characteristics of patients: data-driven analysis of comorbidities. Arthritis Care Res 2015;67:390-5.

7 Wilson JC, Sarsour K, Collinson N, et al. Incidence of outcomes potentially associated with corticosteroid therapy in patients with giant cell arteritis. Semin Arthritis Rheum 2017:46:650-6.

8 Stone $\mathrm{JH}$, Tuckwell K, Dimonaco S, et al. Trial of tocilizumab in giant-cell arteritis. $\mathrm{N}$ Engl J Med Overseas Ed 2017:377:317-28.

9 Villiger PM, Adler S, Kuchen S, et al. Tocilizumab for induction and maintenance of remission in giant cell arteritis: a phase 2, randomised, double-blind, placebocontrolled trial. The Lancet 2016;387:1921-7.

10 Calderón-Goercke M, Loricera J, Aldasoro V, et al. Tocilizumab in giant cell arteritis. observational, open-label multicenter study of 134 patients in clinical practice. Semin Arthritis Rheum 2019:49:126-35.

11 Unizony S, McCulley TJ, Spiera R, et al. Clinical outcomes of patients with giant cell arteritis treated with tocilizumab in real-world clinical practice: decreased incidence of new visual manifestations. Arthritis Res Ther 2021:23:8.

12 Hellmich B, Agueda A, Monti S. Update of the EULAR recommendations for the management of large vessel vasculitis. Ann Rheum Dis 2018;2020:19-30.

13 Strand V, Dimonaco S, Tuckwell K, et al. Health-Related quality of life in patients with giant cell arteritis treated with tocilizumab in a phase 3 randomised controlled trial. Arthritis Res Ther 2019;21:64.

14 Labarca C, Koster MJ, Crowson CS, et al. Predictors of relapse and treatment outcomes in biopsy-proven giant cell arteritis: a retrospective cohort study. Rheumatology 2016;55:347-56.

15 Sugihara T, Hasegawa $\mathrm{H}$, Uchida HA, et al. Associated factors of poor treatment outcomes in patients with giant cell arteritis: clinical implication of large vessel lesions. Arthritis Res Ther 2020;22:72.

16 Restuccia G, Boiardi L, Cavazza A. Flares in biopsy-proven giant cell arteritis in northern Italy: characteristics and predictors in a long-term follow-up study. Medicine2016;95:e3524.

17 Hernández-Rodríguez J, García-Martínez A, Casademont J, et al. A strong initial systemic inflammatory response is associated with higher corticosteroid requirements and longer duration of therapy in patients with giant-cell arteritis. Arthritis Care Res 2002:47:29-35.
18 García-Martínez A, Hernández-Rodríguez J, Espígol-Frigolé G, et al. Clinical relevance of persistently elevated circulating cytokines (tumor necrosis factor $\alpha$ and interleukin-6) in the long-term followup of patients with giant cell arteritis. Arthritis Care Res 2010;62:835-41.

19 Unizony S, Arias-Urdaneta L, Miloslavsky E, et al. Tocilizumab for the treatment of large-vessel vasculitis (giant cell arteritis, Takayasu arteritis) and polymyalgia rheumatica. Arthritis Care Res 2012;64:1720-9.

20 Unizony SH, Dasgupta B, Fisheleva E, et al. Design of the tocilizumab in giant cell arteritis trial. Int J Rheumatol 2013;2013:1-10.

21 Nikiphorou E, Radner H, Chatzidionysiou K, et al. Patient global assessment in measuring disease activity in rheumatoid arthritis: a review of the literature. Arthritis Res Ther 2016;18:251.

22 Yellen SB, Cella DF, Webster K, et al. Measuring fatigue and other anemia-related symptoms with the functional assessment of cancer therapy (FACT) measurement system. J Pain Symptom Manage 1997;13:63-74.

23 Ware JE, Sherbourne CD. The MOS 36-item short-form health survey (SF-36). I. conceptual framework and item selection. Med Care 1992;30:473-83.

24 EuroQol G, EuroQol Group. EuroQol--a new facility for the measurement of healthrelated quality of life. Health Policy 1990;16:199-208.

25 Tuckwell K, Collinson N, Dimonaco S, et al. Newly diagnosed vs. relapsing giant cell arteritis: baseline data from the GiACTA trial. Semin Arthritis Rheum 2017:46:657-64.

26 Broder MS, Sarsour K, Chang E, et al. Corticosteroid-related adverse events in patients with giant cell arteritis: a claims-based analysis. Semin Arthritis Rheum 2016;46:246-52

27 Narvaez J, Nolla-Solé JM, Valverde-García J, et al. Sex differences in temporal arteritis and polymyalgia rheumatica. J Rheumatol 2002;29:321-5.

28 Tsalapaki C, Lazarini A, Antonatou K. THU0310 frequency of relapses and treatment discontinuation during long-term follow-up of patients with giant cell arteritis. Ann Rheum Dis 2017;76:321.

29 Chevalet P, Barrier JH, Pottier P. A randomized, multicenter, controlled trial using intravenous pulses of methylprednisolone in the initial treatment of simple forms of giant cell arteritis: a one year followup study of 164 patients. J Rheumatol 2000;27:1484-91.

30 Soysal P, Stubbs B, Lucato P, et al. Inflammation and frailty in the elderly: a systematic review and meta-analysis. Ageing Res Rev 2016;31:1-8.

31 Wilson D, Jackson T, Sapey E, et al. Frailty and sarcopenia: the potential role of an aged immune system. Ageing Res Rev 2017;36:1-10.

32 Collinson N, Tuckwell K, Habeck F, et al. Development and implementation of a double-blind corticosteroid-tapering regimen for a clinical trial. Int J Rheumatol 2015:2015:1-6. 